\title{
Cost effectiveness of transbronchial needle aspiration
}

\author{
Jennifer A Crocket MD FRCPC ${ }^{1}$, Eric YL Wong MD FRCPC ${ }^{1}$, Dale C Lien MD FRCPC ${ }^{1}$, \\ Khanh Gia Nguyen MD FRCPC ${ }^{2}$, Michelle R Chaput RRT ${ }^{3}$, Ciaran McNamee MD FRCSC ${ }^{4}$ \\ ${ }^{1}$ Pulmonary Division, Department of Medicine and ${ }^{2}$ Department of Laboratory Medicine and \\ Pathology, University of Alberta; ${ }^{3}$ Respiratory Therapy, University of Alberta Hospitals; \\ ${ }^{4}$ Department of Surgery, University of Alberta, Edmonton, Alberta
}

JA Crocket, EYL Wong, DC Lien, GK Nguyen, MR Chaput, C McNamee. Cost effectiveness of transbronchial needle aspiration. Can Respir J 1999;6(4):332-335.

OBJECTIVE: To evaluate the yield and cost effectiveness of transbronchial needle aspiration (TBNA) in the assessment of mediastinal and/or hilar lymphadenopathy.

DESIGN: Retrospective study.

SETTING: A university hospital.

POPULATION STUDIED: Ninety-six patients referred for bronchoscopy with computed tomographic evidence of significant mediastinal or hilar adenopathy.

RESULTS: Ninety-nine patient records were reviewed. Three patients had two separate bronchoscopy procedures. TBNA was positive in 42 patients $(44 \%)$ and negative in 54 patients. Of the 42 patients with a positive aspirate, $40 \mathrm{had}$ malignant cytology and two had cells consistent with benign disease. The positive TBNA result altered management in 22 of 40 patients with malignant disease and one of two patients with benign disease, thereby avoiding further diagnostic procedures. The cost of these subsequent procedures was estimated at $\$ 27,335$. No complications related to TBNA were documented.

CONCLUSIONS: TBNA is a high-yield, safe and cost effective procedure for the diagnosis and staging of bronchogenic cancer.

Key Words: Cost effectiveness; Mediastinal staging; TBNA; Transbronchial needle aspiration

\section{Rapport coût-efficacité de l'aspiration trans- bronchique à l'aiguille}

OBJECTIF : Évaluer le rapport coût-efficacité de l'aspiration transbronchique à l'aiguille (ATA), pratiquée dans les cas d'adénopathie hilaire ou médiastinale.

MÉTHODE : Étude rétrospective.

MILIEU : Centre hospitalier universitaire.

POPULATION ÉTUDIÉE : Quatre-vingt-seize (96) patients dirigés vers le centre hospitalier ont subi une bronchoscopie après qu' une tomographie par ordinateur eut confirmé la présence d'une importante adénopathie hilaire ou médiastinale.

RÉSULTATS : Quatre-vingt-dix-neuf (99) dossiers ont été examinés, dont trois faisaient état de deux bronchoscopies subies par un même patient. L'ATA s'est avérée positive dans 42 cas (44\%) et négative dans 54 cas. Des 42 patients pour qui l'examen a donné des résultats positifs, 40 avaient une cytologie maligne, tandis que l'analyse des cellules pour les deux autres patients était compatible avec une maladie bénigne. Les résultats positifs de l'ATA ont modifié le traitement de 22 des 40 patients atteints d'une maladie maligne et d'un des deux patients porteurs d'une maladie bénigne, évitant ainsi d'autres examens diagnostiques. Le coût des interventions subséquentes a été évalué à 27335 \$. Aucune complication n'a été signalée.

CONCLUSION : L'ATA est une intervention sûre, offrant un bon rapport coût-efficacité pour le diagnostic et la classification en stades des cancers broncho-pulmonaires.

Correspondence and reprints: Dr Eric YL Wong, 2E4.32 Walter C Mackenzie Health Sciences Centre, University of Alberta, Edmonton, Alberta T6G 2B7. Telephone 780-407-7551, fax 780-407-6384, e-mail ewong@ ualberta.ca 
$\mathrm{T}$ ransbronchial needle aspiration (TBNA) of hilar and mediastinal lymph nodes through the flexible bronchoscope has been available for the past two decades and has been shown to be an effective technique in the diagnosis and staging of lung cancer (1). TBNA can sample lymph node areas that are accessible to standard cervical mediastinoscopy thereby avoiding the risks of mediastinoscopy and offering potential cost savings. In addition, TBNA may offer access to lymph nodes that cannot be sampled by cervical mediastinoscopy. Several papers have reported the yield of TBNA (1-7), but the cost effectiveness of TBNA has not been directly studied and only estimated in a hypothetical cohort of patients (8). We retrospectively reviewed our experience with TBNA to examine both the yield and cost effectiveness of the procedure in the Mackenzie Health Sciences Centre, Edmonton, Alberta.

\section{PATIENTS AND METHODS}

The records of all patients who underwent TBNA at the University of Alberta Hospitals, Edmonton, Alberta between February 1996 and February 1998 were reviewed. A total of 96 patients with computed tomography (CT) criteria for significant mediastinal adenopathy (defined as any node greater than $1 \mathrm{~cm}$ in diameter in the short axis), hilar adenopathy or both underwent TBNA. Three patients had two separate bronchoscopy procedures with TBNA because of initial negative results.

Bronchoscopy procedures were performed by staff respirologists or pulmonary residents under direct staff supervision. TBNA was performed before the examination of the bronchial tree, and one to three nodal sites were aspirated using an MV 222 cytology needle (Mill-Rose Laboratories, Mentor, Ohio). The aspirated specimens were smeared and fixed in $95 \%$ alcohol. The TBNA specimens were interpreted by a cytopathologist and considered positive for malignancy when unequivocally malignant cells were present in the specimen. Specimens interpreted as suspicious for carcinoma were considered negative for purposes of the study. Benign disease was more difficult to diagnose with TBNA cytology specimens, but aggregates of epithelioid cells and histiocytes consistent with granulomata were considered positive for sarcoidosis. The false positive and false negative rates of TBNA were not studied; however, no false positive results were suspected clinically.

Patient records were reviewed to determine the indication for bronchoscopy and results of radiographic studies, bronchoscopic findings, cytology and histology reports, surgical pathology reports and eventual outcome. The records of patients with positive TBNA were reviewed by two of the authors (JC, CM) with the intent of determining whether the positive TBNA result altered management and resulted in cost savings by avoiding further diagnostic studies. The authors determined which diagnostic tests would have been necessary in the event that the TBNA had proved negative, and the cost of these subsequent procedures was calculated and compared with the cost of adding TBNA to a routine bronchoscopy procedure.

\section{TABLE 1}

Diagnoses of the study population undergoing transbronchial needle aspiration $(n=96)$

\begin{tabular}{lc}
\hline Diagnosis & N \\
\hline Bronchogenic carcinoma & 56 \\
Lymphoma & 2 \\
Mediastinal/hilar adenopathy in the setting & 7 \\
$\quad$ of nonlung cancer & \\
Sarcoidosis & 9 \\
Mycobacterium tuberculosis & 2 \\
Other benign conditions & 17 \\
Total & $95^{\star}$
\end{tabular}

*One patient lost to follow-up and three patients had two separate procedures

TABLE 2

Histopathological diagnoses for malignant transbronchial needle aspiration

\begin{tabular}{lc}
\hline Diagnosis & Patients N (\%) \\
\hline Adenocarcinoma & $20(50)$ \\
Squamous cell & $6(15)$ \\
Large cell anaplastic & $1(2)$ \\
Small cell & $13(33)$ \\
Total & $40(100)$ \\
\hline
\end{tabular}

RESULTS

Ninety-nine patient records were reviewed. Table 1 depicts the final diagnoses of the study population. Fifty-six patients had bronchogenic carcinoma, while the remainder had a variety of diagnoses including lymphoma, nonlung malignancy, sarcoidosis, pulmonary fibrosis, thyroid mass, bronchiolitis obliterans organizing pneumonia and infection.

Positive aspirates: TBNA was positive and yielded a diagnosis in 42 patients (44\%) and was negative in 54 patients. Of the 42 patients with a positive aspirate, 40 had malignant cytology results and two had cells consistent with benign disease (sarcoidosis). The histopathological diagnoses established in the patients with malignant disease are listed in Table 2.

TBNA was the only positive specimen in 15 of the 56 patients with bronchogenic carcinoma (27\%). Seven of these patients had small cell carcinoma, seven had adenocarcinoma and one had squamous cell carcinoma. The remaining patients with bronchogenic carcinoma were diagnosed by bronchoscopic endobronchial sampling, CT guided transthoracic needle aspiration and thoracotomy.

The positive TBNA result altered further management in 22 of the 40 patients with malignant disease and one of two patients with benign disease. In the remaining 18 patients with malignancy, management was not altered because the tumours were deemed surgically unresectable for reasons including tumour cell type (small cell carcinoma), tumour stage or concurrent medical condition. In the authors' opinion, positive TBNA obviated the need for 15 mediasti- 
TABLE 3

\begin{tabular}{lc}
$\begin{array}{l}\text { Procedures avoided by positive transbronchial needle } \\
\text { aspiration }\end{array}$ \\
\hline Procedure & N \\
\hline Mediastinoscopy & 2 \\
Thoracotomy & 1 \\
Transthoracic needle aspiration & 1 \\
Repeat bronchoscopy & 3 \\
Liver biopsy & 1 \\
Adrenal biopsy & 23 \\
Total
\end{tabular}

noscopy procedures, two thoracotomies and several other procedures, with these procedures summarized in Table 3. Table 4 gives the estimated cost of these procedures.

Negative aspirates: Fifty-four patients had negative TBNA. Three of these patients had a second negative TBNA. Eight patients with negative TBNA underwent cervical mediastinoscopy, and in all cases, the nodes were negative for malignancy and presumed to be benign reactive lymphadenopathy. Ultimately, three of these eight patients had bronchogenic carcinoma, one had lymphoma and four had a benign condition. Four patients with negative TBNA underwent thoracotomy, one of whom also had a mediastinoscopy, and no malignant nodes were identified. One of these patients had bronchogenic carcinoma. Forty-two patients were followed medically; one of whom was lost to follow-up. Twelve patients had inoperable bronchogenic carcinoma, one patient had a history of prior bronchogenic carcinoma with new mediastinal adenopathy, seven had a nonlung primary malignancy, 21 patients had benign disease and one had a thyroid mass.

No complications related to TBNA were documented. Chest radiographs were not routinely performed following the procedure.

\section{DISCUSSION}

TBNA is an established procedure for the diagnosis and staging of lung cancer. The procedure is safe with few complications documented in the literature $(1-7,9,10)$. This is comparable with a complication rate for cervical mediastinoscopy of $2.5 \%$ (11). The literature reports varied diagnostic yields of TBNA in patients with bronchogenic carcinoma. In 1983, Wang et al (1) reported a yield of $49 \%$ in patients with known or suspected bronchogenic carcinoma; all of the patients had a radiographically abnormal mediastinum. In 1994, Wang et al (5) published another paper on a series of patients with pulmonary nodules or masses and/or mediastinal or hilar lesions with a diagnostic yield for TBNA of $89.3 \%$. Shure and Fedullo (2) reported on a series of 110 patients with suspected bronchogenic carcinoma (identified by an abnormal chest radiograph, symptoms or an endoscopic abnormality). Patients underwent transcarinal needle aspiration with a yield of $14.5 \%$. Schenk et al (3) studied a group of 88 patients with suspected bronchogenic carcinoma, 44 of
TABLE 4

Total cost of procedures avoided by transbronchial needle aspiration (TBNA)

\begin{tabular}{lrcr}
\hline Procedure & N & $\begin{array}{c}\text { Cost/unit } \\
\mathbf{( \$ )}\end{array}$ & $\begin{array}{c}\text { Total cost } \\
\mathbf{( \$ )}\end{array}$ \\
\hline Mediastinoscopy & 15 & 1,097 & 16,453 \\
Thoracotomy & 2 & 4,570 & 9,141 \\
$\begin{array}{l}\text { Transthoracic needle } \\
\quad \text { aspirate }\end{array}$ & 1 & 271 & 271 \\
Bronchoscopy (no TBNA) & 1 & 343 & 343 \\
Liver biopsy & 3 & 316 & 949 \\
Adrenal biopsy & 1 & 178 & 178 \\
Total & 23 & & 27,335 \\
\hline
\end{tabular}

whom had significant mediastinal adenopathy on CT scan. Seventeen of the 44 patients had a positive TBNA with a yield of $39 \%$. Utz et al (4) reported a series of 88 patients with bronchogenic cancer with an overall yield of $36 \%$ for subcarinal TBNA and a yield of $43 \%$ in patients with radiographic evidence of subcarinal adenopathy. In 1998, Katis et al (6) reported a prospective study involving 76 patients with chest radiographs suggestive of lung cancer and with evidence of mediastinal adenopathy on CT. Cytological examination of TBNA was positive for malignancy in $72 \%$ of patients.

In the present study, 40 of 56 patients with bronchogenic carcinoma had a positive TBNA, a yield of $71 \%$. All patients had significant mediastinal or hilar adenopathy, or both, on CT scan, and patients with suspected small cell carcinoma or metastatic disease were not specifically excluded.

Positive TBNA obviated the need for further diagnostic procedures in 23 patients. The cost of these procedures was estimated at $\$ 27,335$ versus $\$ 8,405$, the cost of adding TBNA to the 99 bronchoscopy procedures. Additional costs include the TBNA needle and procedure time. One could argue that the liver and adrenal biopsies might have been done before the initial bronchoscopy because they may have provided both a diagnosis and stage. Excluding these procedures, the cost savings remain significant at $\$ 17,802$.

Jain et al (8) performed a cost analysis on a hypothetical cohort of 1000 patients with mediastinal lymphadenopathy. The patients underwent either initial bronchoscopy with TBNA, followed by mediastinoscopy if the TBNA was negative (strategy A) or mediastinoscopy without TBNA (strategy B). They calculated a cost savings of US\$1.67 million/1000 patients by using strategy A.

TBNA is a high-yield, safe and cost effective procedure for the diagnosis and staging of bronchogenic carcinoma. The ability to diagnose and stage patients at the time of initial bronchoscopy simplifies patient management in a cost effective manner. This study supports the findings of Turner and Wong (12) in recommending sequential use of CT and TBNA in the investigation of patients with suspected lung cancer. The yield of TBNA with a cytology needle is much lower for benign disease, and consideration should be given to using a histology needle when a benign process is suspected. 


\section{REFERENCES}

1. Wang KP, Brower R, Haponik EF, Siegelman S. Flexible transbronchial needle aspiration for staging of bronchogenic carcinoma. Chest 1983;84:571-6.

2. Shure D, Fedullo PF. The role of transcarinal needle aspiration in the staging of bronchogenic carcinoma. Chest 1984;86:693-6.

3. Schenk DA, Bower JH, Bryan CL, et al. Transbronchial needle aspiration staging of bronchogenic carcinoma. Am Rev Respir Dis 1986; $134: 146-8$

4. Utz J, Patel AM, Edell ES. The role of transcarinal needle aspiration in the staging of bronchogenic carcinoma. Chest 1993;104:1012-6.

5. Wang KP, Gonullu U, Baker R. Transbronchial needle aspiration versus transthoracic needle aspiration in the diagnosis of pulmonary lesions. J Bronchol 1994;1:199-204.

6. Katis K, Kotrogiannis G, Paraskevopoulos I, et al. Bronchoscopic needle aspiration in mediastinal staging of patients with bronchogenic carcinoma. J Bronchol 1998;5:195-9.
7. Harkin TJ, Wang KP. Bronchoscopic needle aspiration of mediastinal and hilar lymph nodes. J Bronchol 1997;4:238-49.

8. Jain P, Arroliga A, Mehta AC. Cost-effectiveness of transbronchial needle aspiration in the staging of lung cancer. Chest 1996;110:24S. (Abst)

9. Harrow EM, Wang KP. The staging of lung cancer by bronchoscopic transbronchial needle aspiration. Chest Surg Clin North Am 1996;6:223-35.

10. Dasgupta A, Mehta AC, Wang KP. Transbronchial needle aspiration. Semin Respir Crit Care Med 1997;18:571-81.

11. Kirschner PA. Cervical mediastinoscopy. Chest Surg Clin North Am 1996;6:1-20.

12. Turner JF, Wang KP. Staging of mediastinal involvement in lung cancer by bronchoscopic needle aspiration. J Bronchol 1996;3:74-6.

\section{BOOK REVIEW}

Year Book of Pulmonary Disease 1998, edited by James Jett, Janet Maurer, Jay Ryu, Patrick Strollo, Sally Wenzel (1998). Mosby, a division of Harcourt Brace Canada, 55 Horner Avenue, Toronto, Ontario M8Z 4X6. ISBN 0-81151-9736-5; 453 pages; $\$ 119.00$

The stated purpose of the Year Book series is to survey a wide range of proven journals to select significant advances and important clinical principles, to abstract those articles, and to provide appropriate commentary to place them in perspective. In accomplishing these objectives, the Year Book of Pulmonary Disease 1998 succeeds very well. Sixty journals are reviewed, representing pulmonary disease, infectious diseases, surgery, anaesthesia, general medicine, cardiovascular disease, emergency medicine, epidemiology, radiology, pathology, sleep, critical care, and allergy and immunology. The pulmonary disease year book appears to cover these publications in 1996 and 1997. The internationally known editor and four associate editors provide the abstracts, and give a critique of each paper that consistently balanced and pertinent. The comments are well referenced. Despite the multiple authorship, the style is remarkably clear, consistent and unbiased. The choice of literature reviewed is certainly comprehensive and appropriate.

The question is the readership for which this volume is best suited and the niche that it may fill in this day of rapid access to MEDLINE and review series such as Uptodate or Silverplatter that are provided at three or four months intervals. Thus, this is not a volume that a reader will use to review the literature on a specific problem because it is six to 24 months behind and may not contain important information published before 1996. Admittedly, this earlier data may be discussed in the commentary.

Where, then, might a book such as this fit into the reading schedule of a busy respirologist? I believe that it should be read, or at least scanned by both academic and practicing respirologists as well as fellows preparing for their examinations (it provides excellent airplane reading). Thus, it should be considered complimentary to MEDLINE or Uptodate. However, it may be that the days of this type of volume are numbered. A modification of the format should be considered in keeping with the times. It would serve best as a quarterly review journal of pulmonary disease analogous to the ACP Journal Club, which comes out bimonthly and summarizes advances in general medicine with editorial comments. In this way, it would be more up to date and function more effectively for the pulmonary specialists who do not have time to read everything and who appreciate the critical comments of the experts.

Morley Lertzman MD Department of Respiratory Medicine St Boniface General Hospital Winnipeg, Manitoba 




The Scientific World Journal


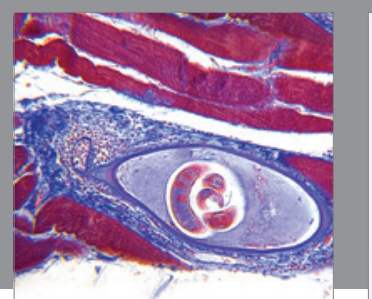

Gastroenterology Research and Practice

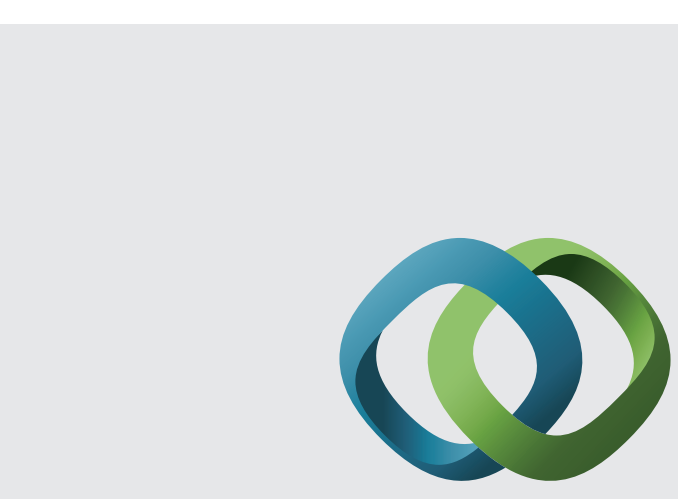

\section{Hindawi}

Submit your manuscripts at

http://www.hindawi.com
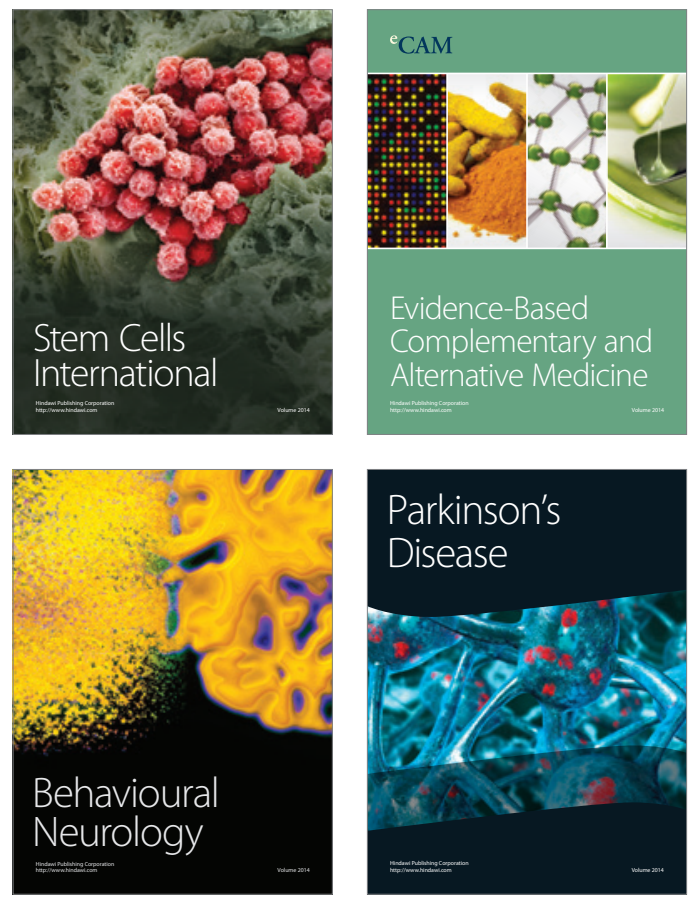
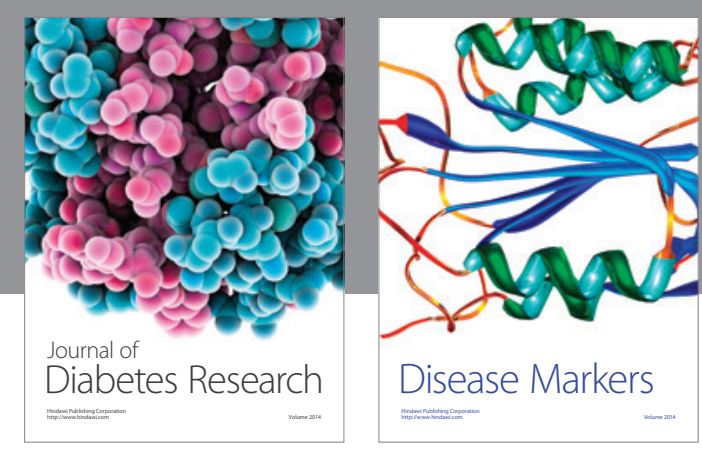

Disease Markers
